\title{
Successful medical treatment of a hepatic pregnancy: a case report
}

\author{
A. Sibetcheu Tchatou ${ }^{1 *}$, R. Tchounzou², L. Mbuagbaw ${ }^{3}$ and E. T. Mboudou²
}

\begin{abstract}
Background: Hepatic pregnancy is a rare form of abdominal pregnancy, often documented only as case reports. Case presentation: We report here the case of a 24-year-old African woman, gravida 4 para 3, presenting with right upper quadrant pains and metrorrhagia after amenorrhea of 8 weeks 5 days. Elements in favor of the diagnosis of hepatic pregnancy were her clinical presentation, the kinetics of $\beta$-human chorionic gonadotropin titers, and the presence of a sub-hepatic mass on ultrasound. We successfully treated this patient with intramuscular methotrexate only.

Conclusions: The interest of this case resides in the rarity of this condition and the therapeutic approach used. Clinicians should raise their index of suspicion for hepatic pregnancy when faced with females of reproductive age with such a clinical presentation.
\end{abstract}

Keywords: Hepatic pregnancy, Methotrexate, Case report, Cameroon

\section{Background}

Abdominal pregnancies constitute $1.4 \%$ of ectopic pregnancies. This rare form of ectopic pregnancy is associated with high mortality due to diagnostic challenges and the massive intraperitoneal hemorrhage caused by the removal of the placenta [1]. A hepatic location is extremely rare and described only as case reports. In these circumstances, treatment options are not as well defined as they are with tubal ectopic pregnancy. We present this case of hepatic pregnancy diagnosed with noninvasive explorations and medical treatment.

\section{Case presentation}

A 24-year-old African woman, gravida 4 para 3, presented with a 2-week history of right upper quadrant pain and an 8 weeks and 5 days amenorrhea with spotting. She first consulted in a secondary health facility where her clinical evaluation revealed a hepatomegaly on abdominopelvic ultrasound and positive urinary pregnancy test without intrauterine or tubal gestational sac. These findings motivated the medical team to refer her to our tertiary center.

\footnotetext{
* Correspondence: asibetcheu@gmail.com

${ }^{1}$ Faculty of Medicine and Biomedical Sciences, University of Yaounde I,

Yaounde, Cameroon

Full list of author information is available at the end of the article
}

This was her first episode of such pain. She had no history of sexually transmitted diseases and no history of contraception. She had never had an operation. Her hepatitis $B$ and $C$ status were unknown. There was no dizziness, asthenia, or jaundice.

Her vital signs were stable: blood pressure of 120/ $60 \mathrm{~mm} \mathrm{Hg}$, pulse rate of 70 beats per minute, respiratory rate of 16 cycles per minute, and temperature at $36.5^{\circ} \mathrm{C}$. She weighed $59 \mathrm{~kg}$. She was not pale. Her right upper quadrant was tender on deep palpation but not after deep breath. There was no guarding or rebound tenderness. Her uterus was of normal size and there were no adnexal masses noted. Her rectovaginal pouch was free and non-tender. We suspected acute cholecystitis or acute viral hepatitis in pregnancy.

On another abdominopelvic ultrasound, a heterogeneous poorly vascularized mass was visible under the right lobe of her liver, of size $42 \times 38 \mathrm{~mm}$. There was no hemoperitoneum and her uterus was empty without adnexal masses. On full blood count, there was mild microcytic and hypochromic anemia at $10.2 \mathrm{~g}$ per $\mathrm{dL}$, with normal leukocyte and platelet counts. Her liver transaminases and renal function were normal. Her serum $\beta$-human chorionic gonadotropin ( $\beta$ hCG) titers rose from $200 \mathrm{mUI} / \mathrm{mL}$ to $3000 \mathrm{mUI} / \mathrm{mL}$ in 48 hours. No gestational sac was visible on concomitant pelvic ultrasound. 
Our final diagnosis was hepatic pregnancy. We chose to administer $1 \mathrm{mg} / \mathrm{kg}$ of methotrexate intramuscularly since she was hemodynamically stable and the Fernandez score [2] was in favor of medical treatment. Evolution was favorable and she was discharged at day 5. Two weeks later, her serum $\beta$ hCG titer was $15 \mathrm{mUI} / \mathrm{mL}$. She did not show up at 1-month appointment.

\section{Discussion}

Abdominal pregnancy is a rare form of ectopic pregnancy. It occurs in 9.2 per 1000 ectopic pregnancies [1]. Location in the liver is extremely rare. Using "hepatic pregnancy", "hepatic ectopic pregnancy", and "primary hepatic pregnancy" as keywords in PubMed, only 21 cases have been reported in the English literature of which four were in Africa [3-6], and of the 21 reported cases, one had medical treatment only [7].

Of these 21 cases, $61.9 \%$ of cases presented with abdominal pain and signs of hemoperitoneum on admission or during hospitalization. Other nonspecific signs included localized abdominal tenderness (right upper quadrant, right flank), spotting, and right upper quadrant masses with amenorrhea. These misleading signs may point clinicians toward digestive and hepatobiliary pathologies, thus delaying the diagnosis.

Abdominal ultrasound is a first-line medical imaging modality in the diagnosis of ectopic pregnancy. However, the accuracy is better with magnetic resonance imaging (MRI), especially in describing the regional anatomy, the precise location of the placenta, and key elements to determine whether the placenta should be removed or not [8]. Ultrasounds coupled with the $\beta$ hCG titers were the only available and affordable means of diagnosis used for this patient. The site mostly described in the literature is under the right lobe of the liver, as in our case [5-7].

The management of hepatic pregnancies is variable. Surgery, either laparotomy or laparoscopy, is the most described and used therapeutic option. The main challenge with this technique is the cataclysmic hemorrhage that can occur during surgery. One patient died of multiorgan failure secondary to an uncontrollable bleeding from the placenta site left in situ [9]. Common surgical procedures used include hepatic artery ligation, lobectomy, omental transplantation, and liver packing. Other authors administered a direct injection of methotrexate during a diagnostic laparotomy [10] or a combination of preoperative arterial embolization, laparoscopic extraction of the fetus, and postoperative administration of methotrexate for the placenta left in situ [11].

The hemodynamic stability of our patient and the favorable Fernandez score prompted us to choose the least invasive approach, administration of methotrexate intramuscularly at a dose of $1 \mathrm{mg} / \mathrm{kg}$. This dose was repeated 7 days later, as a precaution since a $15 \%$ reduction in
BhCG titers had been obtained. This medical approach is similar to what Shippey et al. did [7].

\section{Conclusions}

As clinicians, we should always rule out hepatic pregnancy when faced with such a clinical presentation. Intramuscular injection of methotrexate to the mother is the least invasive treatment option reported in the treatment of hepatic pregnancies. It could be a safe therapeutic option in uncomplicated forms of this rare condition.

\section{Acknowledgements}

Not applicable.

Funding

Not applicable.

Availability of data and materials

Not applicable.

Authors' contributions

AST wrote the case report; RT, LM, and ETM reviewed the manuscript and corrected it. All authors read and approved the final manuscript.

\section{Competing interests}

The authors declare that they have no competing interests.

\section{Consent for publication}

Written informed consent was obtained from the patient for publication of this case report and any accompanying images. A copy of the written consent is available for review by the Editor-in-Chief of this journal.

Ethics approval and consent to participate

Not applicable.

\section{Author details}

${ }^{1}$ Faculty of Medicine and Biomedical Sciences, University of Yaounde I, Yaounde, Cameroon. ${ }^{2}$ Gynaecology and Obstetrics Unit, Douala Gynaeco-Obstetric and Paediatric Hospital, Douala, Cameroon. ${ }^{3}$ Department of Clinical Epidemiology and Biostatistics, McMaster University, Hamilton, Canada.

Received: 4 September 2016 Accepted: 30 January 2017

Published online: 15 March 2017

\section{References}

1. Atrash HK, Friede A, Hogue CJ. Abdominal pregnancy in the United States: frequency and maternal mortality. Obstet Gynecol. 1987;69(3 Pt 1):333-7.

2. Fernandez $\mathrm{H}$, Lelaidier $\mathrm{C}$, Thouvenez V, Frydeman R. The use of a pretherapeutic, predictive score to determine inclusion criteria for the nonsurgical treatment of ectopic pregnancy. Hum Reprod. 1991;6(7):995-8.

3. Mitchell RW, Teare AJ. Primary hepatic pregnancy. A case report and review. South Afr Med J Suid-Afr Tydskr Vir Geneeskd. 1984;65(6):220.

4. Luwuliza-Kirunda JM. Primary hepatic pregnancy. Case report. Br J Obstet Gynaecol. 1978;85(4):311-3.

5. Brouard KJ, Howard BR, Dyer RA. Hepatic Pregnancy Suspected at Term and Successful Delivery of a Live Neonate With Placental Attachment to the Right Lobe of the Liver. Obstet Gynecol. 2015;126(1):207-10.

6. Ramphal SR, Moodley J, Rajaruthnam D. Hepatic pregnancy managed conservatively. Trop Doct. 2010;40(2):121-2.

7. Shippey SH, Bhoola SM, Royek AB, Long ME. Diagnosis and management of hepatic ectopic pregnancy. Obstet Gynecol. 2007;109(2 Pt2):544-6.

8. Veress B, Wallmander T. Primary hepatic pregnancy. Acta Obstet Gynecol Scand. 1987;66(6):563-4

9. Yadav R, Raghunandan C, Agarwal S, Dhingra S, Chowdhary S. Primary hepatic pregnancy. J Emerg Trauma Shock. 2012;5(4):367-9. 
10. Nichols C, Koong D, Faulkner K, Thompson G. A Hepatic Ectopic Pregnancy Treated with Direct Methotrexate Injection. Aust N Z J Obstet Gynaecol. 1995;35(2):221-3.

11. Rahaman J, Berkowitz R, Mitty H, Gaddipati S, Brown B, Nezhat F. Minimally invasive management of an advanced abdominal pregnancy. Obstet Gynecol. 2004;103(5 Pt 2):1064-8.

Submit your next manuscript to BioMed Central and we will help you at every step:

- We accept pre-submission inquiries

- Our selector tool helps you to find the most relevant journal

- We provide round the clock customer support

- Convenient online submission

- Thorough peer review

- Inclusion in PubMed and all major indexing services

- Maximum visibility for your research

Submit your manuscript at www.biomedcentral.com/submit 